\title{
A Real-Time Decision Support System for River Basin Management
}

\author{
Ayushi Vyas ${ }^{1, a}$ and Siby John ${ }^{2}$ \\ ${ }^{1,2}$ PEC University of Technology, Environmental Department, Chandigarh
}

\begin{abstract}
The applications of computer technology to analysis of the rainfall-runoff process and the hydrological dynamics of natural rivers have greatly expanded in the past few years. A large number of general purpose programs and a few programs designed for specific application have been developed and applied to hydrologic engineering problems. This paper briefly describes the study of climate change effects on the hydrological dynamics of the Satluj and Beas river system using computer models like HEC- RTS (Hydrologic Engineering Center- Real Time Simulation). It also presents the use of real time data collection and processing on a GIS platform so as to derive a real time decision support system.
\end{abstract}

Keywords: DSS, hydrology, modeling, hydrologic model.

\section{Introduction}

Hydrologic engineering has traditionally been one of the areas which required management and massive amount of data. With the help of the analytical capability provided by the use of computers only, hydrologic engineers can continue to respond to the ever-increasing demands for more comprehensive and more complex hydrologic studies [1]. Simulation speed and data visualisation are of great significance to decision making. Real-time interaction during the simulation process is also very important for dealing with different conditions and for making timely decisions [2]. Currently, the major challenge for decision-makers and stakeholders in the water sector is to understand the effects of global warming and to determine where and how regions and sectors are vulnerable and to implement appropriate adaptation measures.

Considering the recent technological and methodological developments, this study deals with the climate change effects on the hydrological dynamics of river system including the real time data acquisition. This research provides a conceptual basis for real-time multipurpose data assembling, evaluating, modeling and visualisation towards the operationalisation of decisions. Turning field observations into useful real-time decision support information is demonstrated based on a hydrological example of Integrated Water Resource Management. Decision Support Systems (IWRM-DSS) based on a virtual environment are becoming a popular platform in watershed simulation and management. By carrying out simulation and verification of hydrological models of river basin in HEC-RTS, a continuous

\footnotetext{
a Ayushi Vyas: ayushi.vyas4@gmail.com
}

monitoring of runoff level is being made. A real time decision support system for the river system using GIS and computer model is developed and made functional.

\section{Study Area}

The study area is Satluj and Beas basin as depicted in the figure 1 below.

\subsection{The Satluj}

It has its source in one of the westerly Mansarovar lake in Tibet located at $30^{\circ} 20^{\prime} \mathrm{N}$ and $81^{\circ} 25^{\prime} \mathrm{E}$ at an elevation of 4633 meters above sea level. Satluj is an antecedent stream. After originating, the Satluj follows a northwesterly course along the slopes of Kailash Mountain before entering the Shipki La. Thence it bends southwest and it enters the Shivalik foothills near Nangal. A few miles above, the Bhakra dam has been constructed across the river. At this point, the river flows with northwest-southeast orientation through the Jaswan dun between two ranges of the Shivalik hills in Ropar district. At Ropar it pierces through the hills and enters the plain proper, and here it takes a sharp westward turn. The Satluj separates the Bist Doab in the north from the Malwa tract in the south. At Harike it is joined by the Beas. Of the total length of about $1450 \mathrm{kms}$, the Satluj flows for about $1050 \mathrm{kms}$ in the east and drains about 25,900 sq.kms of area.

\subsection{The Beas}


Beas rises from the southern face of Rohtang Pass in the Kullu district. After its hill journey it enters the Punjab plain near Mirthal where it is joined by the Chakki stream. The Beas joins the Satluj at Harike after flowing over a hundred and fifty kilometers, separating the upper Bari Doab from the Bist Doab. Before the sudden westward turn of the Satluj, the Beas was a big river, flowing separately to join the Ravi some distance south of Multan. At that time it traversed through a large part of the Punjab plain. At present Beas is a comparatively small river which is only about $460 \mathrm{kms}$ long and lies entirely within the eastern territory. Its total catchment area is about 20,000 sq. kms.

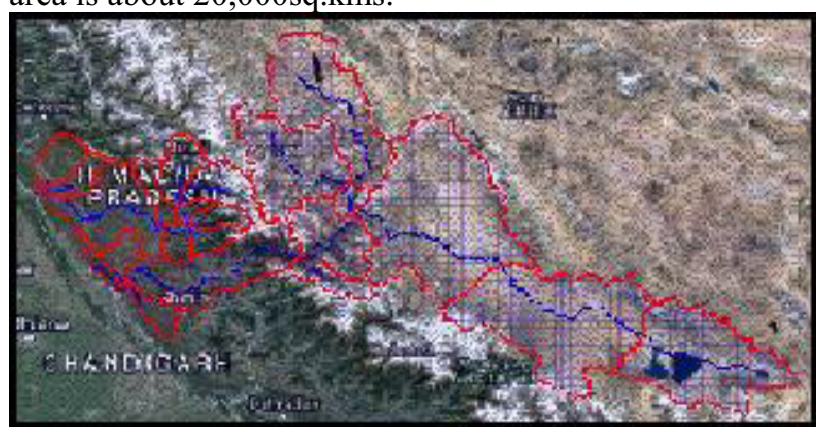

Figure 1. Satluj and Beas river basin.

\section{Model Concept}

\subsection{Hydrologic Modeling}

Hydrological modeling is a tool used to estimate the basin's hydrological response due to precipitation [3]. The objective of hydrological modeling is to gain a better understanding of the hydrologic phenomena operating in a watershed and of how changes in the watershed may affect these phenomena [4]. They are also valuable for studying the potential impacts of changes in climate. Runoff is an indication of availability of water. Generally, the reservoir inflow is deducted as a byproduct of the reservoir balance. The recent approach uses remote sensed data facilitate modeling activities of the flow using a hydrological model [13]. Hydrologic model can be classified into three main categories which are lumped, semi-distributed and distributed models. The model uses several components to simulate the hydrological behavior of the basin [5]. These hydrological elements use mathematical functions to describe the physical processes in the watershed.

\subsection{Applications}

The daily stream flows can be computed using the HECRTS model and the prepared data maps are used in the model. Watershed and meteorology information were combined to simulate the hydrologic responses [10]. Data required for the hydrological modeling are area of the catchment and the sub catchments, daily rainfall data, imperviousness, constant rate, time of concentration and storage coefficient. These values were taken considering the prominent soil type in the catchment area.

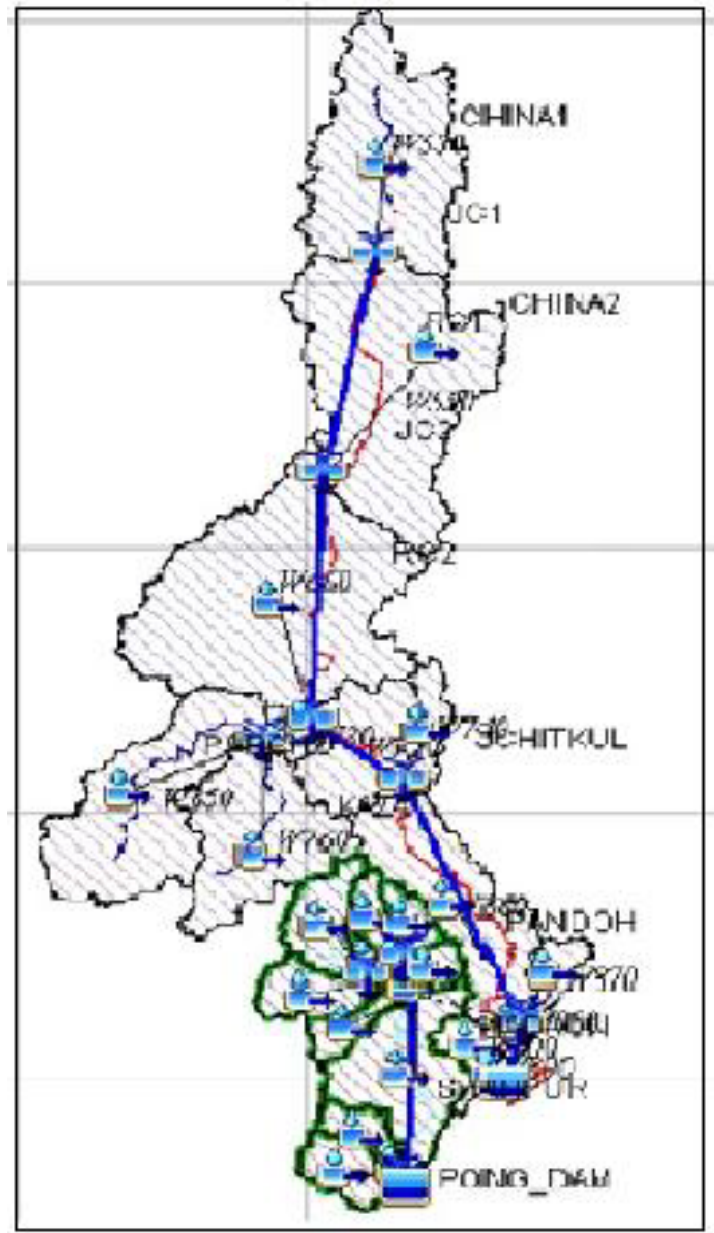

Figure2. The gridded view of Satluj- Beas river basin generated to analyze runoff by initial and constant loss model.

Precipitation on the pervious surfaces is subject to losses. The initial and constant-rate loss model is included to account for the cumulative losses. The underlying concept of the initial and constant-rate loss model is that the maximum potential rate of precipitation loss, $f_{c}$, is constant throughout an event. Thus, if $p_{t}$ is the mean areal precipitation depth during a time interval $t$ to $t+\Delta t$, the excess, $p_{e t}$, during the interval is given by:

$$
p_{e t}=\left\{\begin{array}{c}
p_{\mathrm{t}}-\mathrm{f}_{\mathrm{c}} \text { if } \mathrm{p}_{\mathrm{t}}>\mathrm{f}_{\mathrm{c}} \\
0 \text { otherwise. }
\end{array}\right\}
$$

Precipitation loss is found for each computation time interval, and is subtracted from the mean areal precipitation depth for that interval. The remaining depth is referred to as precipitation excess [14]. This depth is considered uniformly distributed over a watershed area, so it represents a volume of runoff as precipitation excess $\&$ represents volume of runoff [6]. To use the ModClark model, a gridded representation of the watershed is defined. Information about this representation is stored in a grid-parameter file as model is working on grid file format. HEC-HMS uses separate models to represent each component of the runoff process, including models that compute runoff volume, models of direct runoff, and models of base flow. To compute the direct runoff, the program uses a discrete representation of excess precipitation, in which excess precipitation is known for 
each time interval. It then solves the discrete convolution equation for a linear system:

$$
\mathrm{Q}_{\mathrm{n}}=\sum \mathrm{P}_{\mathrm{m}} \mathrm{U}_{\mathrm{n}-\mathrm{m}+1}
$$

Where $\sum$ varies from $\mathrm{m}=1$ to $\mathrm{n} \leq \mathrm{M} ; Q_{n}=$ hydrograph ordinate at time $n \Delta t ; P_{m}=$ rainfall excess depth in time interval $m \Delta t$ to $(m+1) \Delta t ; M=$ total number of discrete rainfall pulses; and $U_{n-m+1}=$ Unit Hydrograph ordinate at time $(n-m+1) \Delta t . Q_{n}$ and $P_{m}$ are expressed as flow rate and depth respectively, and $U_{n^{-} m+1}$ has dimensions of flow rate per unit depth [15].

\section{Real Time Data Acquisition}

\subsection{Data Acquisition}

Hydrological processes are highly dynamic in nature. Conventional methods for the estimation of the hydrologic state variables are based on the point measurements. Obsolete communication systems, partial coverage of catchment area, forecasts variance, poor decision making tools and dependence on remote man power, enormous instrumental requirements and the physical inaccessibility of the areas often limit the observed data availability [7]. This section briefly explains the application of remote sensing techniques for the estimation of the hydrologic state variables such as precipitation and temperature which are the major inputs in any hydrological model.

\subsubsection{Precipitation}

The most important input information for a hydrologic model is precipitation. The most common form applied in modeling is gauge data. Gauge data is input as point data and generally assumed to be constant across a sub-basin. Satellite-derived rainfall estimate generated by the National Oceanic and Atmospheric Administration (NOAA) and the National Aeronautic and Space Administration (NASA) are used to drive a hydrologic model. NASA Satellites for Water Quantities are Landsat, TRMM (Tropical Rainfall Measuring Mission), GPM (Global Precipitation Measurements System), Terra, Aqua and GRACE (Gravity Recovery and Climate Experiment).

\subsubsection{Temperature}

Earlier lapse rate method was used to estimate temperature of inaccessible areas but now many sources for remote sensed data are available. The temperature data can be collected from IMD (FTP- Server) and RIMES (Regional Integrated Multi-hazard Early Warning System for Asia and Africa). IMD AWS (Automated Weather Stations) and IMD ARG (Automated Rain Gauges) provide temperature data which can be used in hydrological models [8].

\subsection{Real-time Data Processing}

\subsubsection{Time series formation}

Time series data are an integral part of hydrologic data. Once the precipitation and temperature records have been downloaded, quality checks are to be applied for consistency, removal of spikes and faulty data and interpolation technique for missing data [11]. Then these are assigned to the watersheds they are transferred from geo-database time series tables to HEC-DSS (Hydrologic Engineering Center-Data Storage System) binary format. The modeling features in a hydrologic or hydraulic simulation model must be uniquely identified so that input and output time series associated with them can be labeled appropriately. A geodatabase structure in Arc Hydro that exactly mimics HEC-DSS components must be created so that the ArcGIS geodatabase can contain a mirror image of the time series information for model elements stored in HEC-RTS (which share HEC-DSS as their time series data storage system). This means two related tables, a catalog and a time series table. A software application must interpret the HEC-DSS time series catalog and know which time series records apply to a particular model feature.

\subsubsection{Linking of real-time data with hydrological models.}

Basin model along with the meteorological data in form of time series grid files can be visualized and analyzed on HEC-RTS user interface. Both temperature and precipitation variable can be presented on the Digital Elevation Model (DEM) of the basin under study. The representation of precipitation is shown in figure 3 .

Moreover by providing precipitation and temperature data snow water equivalent can be calculated. Snow water equivalent (SWE) is an important parameter which is used in hydrological modeling of snow-covered basins. Once this parameter is determined, it can be verified using MODIS snow cover imaginaries.

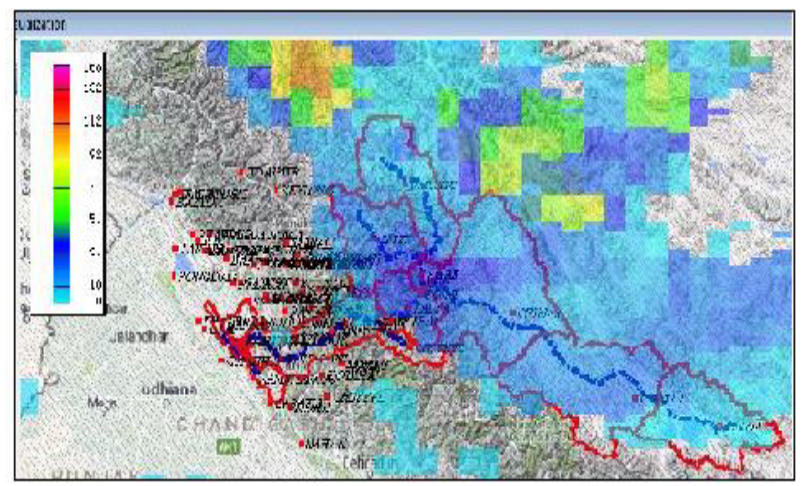

Figure 3. Grid display of precipitation data on basin model.

SWE provide important information for water resource management and is a major research topic in assessment of snow cover and melt. Estimation of SWE proves useful in determining the exact amount of runoff in snow covered basins. 


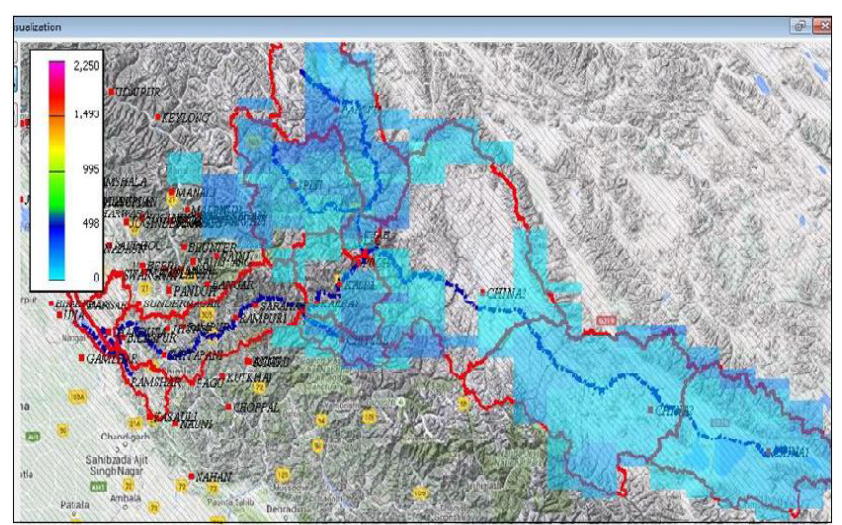

Figure 4. SWE calculated by linking real time precipitation and temperature data with the model.

\section{Results and Discussion}

The hydrology and dynamics of Satluj and Beas river basin including the real time data acquisition is studied here by making a hydrological model work for the basin. By linking of real time data with hydrological model, basin model along with the meteorological data in form of time series grid files can be visualized and analyzed on HEC-RTS user interface. Study also aim to carry out simulation and verification of hydrological models of river basin in HEC-RTS.

Figures 5 show the current performance of model in calculation of inflow in Bhakra reservoir and depict the observed and simulated runoff volume results.

Similarly calculations can be performed for Pong reservoir and presented in figure 6 and 7.

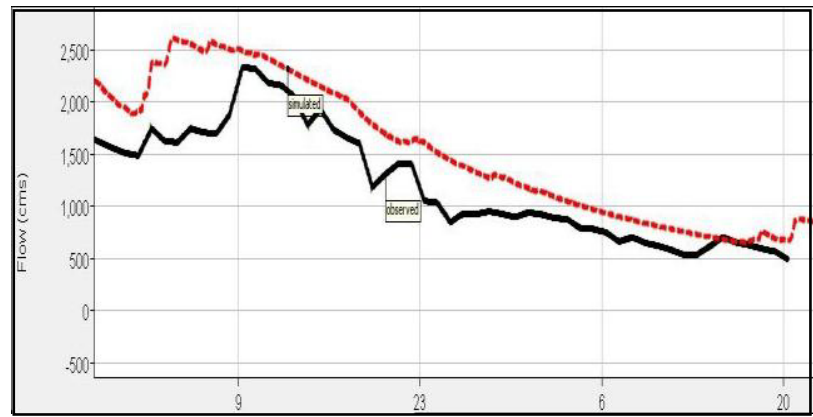

Figure 5. Current model performance for Bhakra reservoir.
Moreover for individual sub-catchments of river Satluj and Beas the various parameters like flow, temperature, precipitation and SWE can be computed and presented.

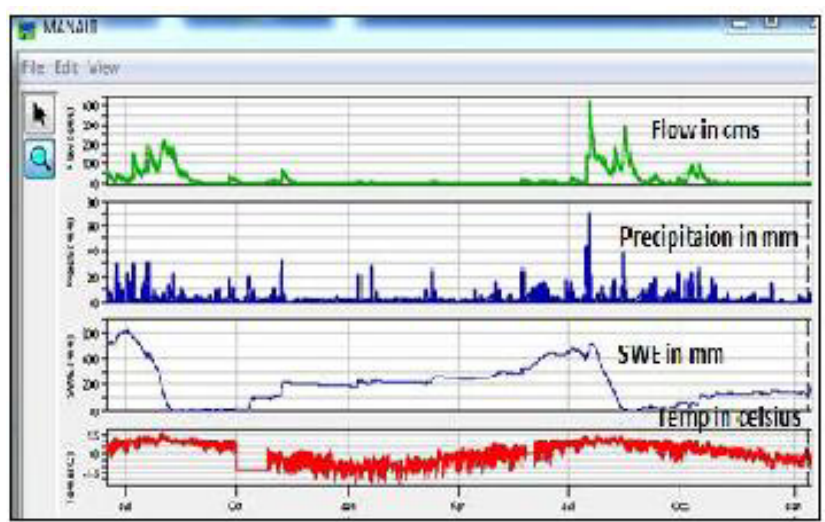

Figure 6. HEC-RTS model providing details regarding subcatchment of Beas basin.

Real time data acquisition and presentation on a potential interactive platform is important and attempts to develop an interactive Decision Support System using the real time data acquisition in river systems is made successful. Some necessary calibration has yet to be done before the climate models judged for reliability of their outcomes to carry out the hydrological research. While models are clearly getting more comprehensive, it is yet unclear how much of their convergence with observations is due to better understanding of the processes or due to increased realism in parameterization [9]. Different combinations of simulation models for hydrological modeling have yet to be tried for the Indian River basin. And then can we really effectively strategize their management to combat the water crisis in the changing climate [10]. Furthermore, there is an urgent need of integrated research by engineers and hydrologists which would yield a wholesome solution like a complete real time decision support system.

\section{Conclusions}

The present trends point to increasing several innovations. Availabilty of data from multiple sensors

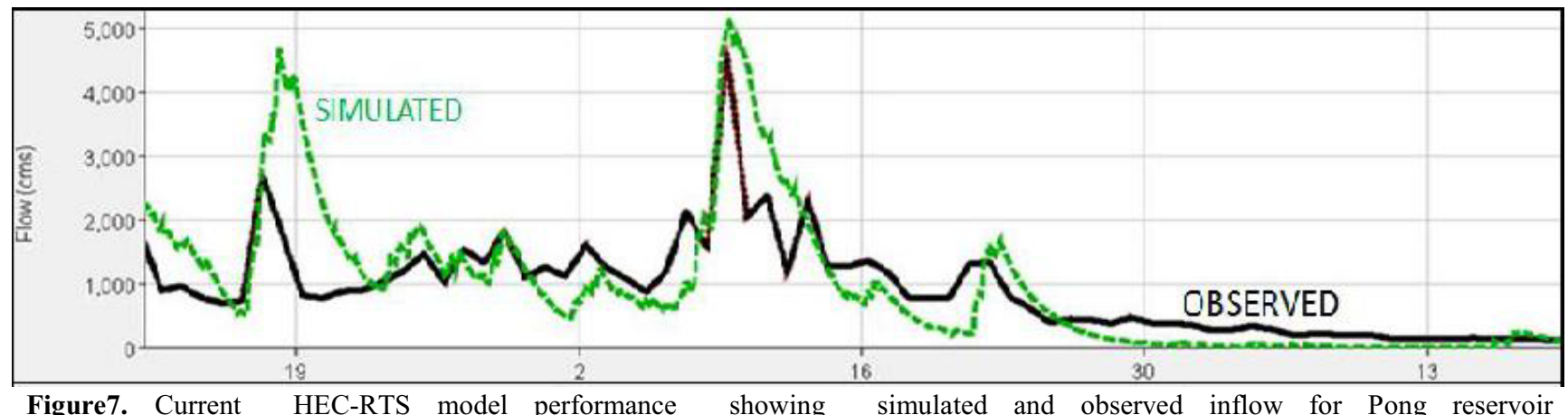


with wide array of spatial, spectral, and radiometric characteristics and this data will be available from multiple sources. Therefore, significant advances have been made in harmonizing and synthesizing data from multiple sources that facilitates the use of data from these sensors of widely differing characteristics and sources. The micro satellites that specialize in gathering data for specific geographic location and for particular applications are likely to become more attractive. For many environmental and natural resource applications global wall-to-wall coverage is essential and here NASA satellites will continue to play most important role. Moreover, hydrological models like HEC-RTS which works on real time simulations are making difference in the conventional methods of modeling. The advances made in data synthesis, presentation, and accessibility through such systems will bring in new users and multiply applications of remote sensing in environmental sciences and natural resources management.

\section{References}

1. A. Aghakouchak, E. Habib, Int. J. Engng Ed. 26, pp. 963-973 (2010)

2. K. P. Georgakakos, N. E. Graham, T. M. Modrick, M. J. Murphy Jr, E. Shamir, C. R. Spencer, J. A. Sperfslage, Journal of Hydrology, 519, pp. 2978-3000 (2014)

3. K. Choudhari, B. Panigrahi, J.C. Paul, Int. J. of Geomatics and Geosciences, 5, pp.253-265 (2014)

4. D. Bhatt, R.K. Mall, Aquatic Procedia 4, pp. 730 738 ( 2015 )

5. D. Halwatura, M. Najim., Environmental Modelling \& Software 46, pp. 155-162 (2013)

6. M.K. Yener, A.Ü. Şorman, A.A. Șensoy,T. Gezgin, Int. J. River Basin Management, pp. 621-634 (2010)

7. C. Giardino, M. Bresciani, P. Villa, A. Martinelli, Water Resour Manage 24, pp.3885-3899 (2010).

8. R.A. Mir, S. Jain, A.K. Saraf, A. Goswami, J. Earth Syst. Sci. 124, pp. 365-382, (2015)

9. D. Bhatt, R.K. Mall, Aquatic Procedia 4, pp. $730-$ 738 (2015)

10. R. Ragab, C. Prudhomme, Biosystems Engineering 81 pp. 3-34 (2002).

11. P. Singh, A. Gupta, M. Singh, Egyptian J. Remote Sensing and Space Sciences 17, pp 111-121 (2014)

12. X. Zhang, R. Srinivasan, K. Zhao, M.V. Liew, J. Hydrologic Engineering 19, pp. 1374-1384 (2014)

13. M.F. Baumgartner, G.M. Apfl, Hyémlogkal Sciences -Journal- des Sciences $\mathrm{B}^{\wedge}$ dmlagiqmes 41 pp. 593-607 (1996)

14. K.M. Loague, R.A. Freeze, J. Water Resource Research 21 pp. 229-248 (1985).

15. V.T. Chow, D.R. Maidment, L.W. Mays, Applied Hydrology NY (1988) 